\title{
Coastal Resources Economics and Ecosystem Valuation
}

\author{
J. Walter Milon ${ }^{1, *}$ and Sergio Alvarez ${ }^{2}$ \\ 1 Department of Economics, University of Central Florida, Orlando, FL 32816, USA \\ 2 Rosen College of Hospitality Management, University of Central Florida, Orlando, FL 32816, USA; \\ sergio.alvarez@ucf.edu \\ * Correspondence: jmilon@ucf.edu
}

Received: 11 October 2019; Accepted: 16 October 2019; Published: 23 October 2019

\begin{abstract}
The papers in this special issue provide new insights into ongoing research to value coastal and marine ecosystem services, and offer meaningful information for policymakers and resource managers about the economic significance of coastal resources for planning, restoration, and damage assessment. Study areas encompass a broad geographic scope from the Gulf of Mexico in the United States, to the Caribbean, the European Union, Australia, and Southeast Asia. The focus of these papers ranges from theoretical perspectives on linkages between ecosystem services and resource management, to the actual integration of valuation information in coastal and marine resource policy decisions, and to the application of economic valuation methods to specific coastal and marine resource management problems. We hope readers will appreciate these new contributions to the growing literature on coastal and marine resource ecosystem services valuation.
\end{abstract}

Keywords: environmental valuation; coastal ecosystem services valuation; coastal management; ecosystem restoration

\section{Introduction}

Coastal areas around the world are dynamic environments at the interface of terrestrial, marine, and freshwater systems. Nearly 2.4 billion or $40 \%$ of the world's people already live in these areas [1]. Coastal zones are increasingly attractive for development and tourism. However, the coastal ecosystems within these zones are vulnerable to a variety of impacts from anthropogenic activities, resulting in excess nutrients, invasive species, extreme weather, sea level rise, and oil spills, among others. These coastal ecosystems include, but are not limited to: estuaries, beaches, wetlands, shores, mangroves, seagrasses and salt marsh, coral reefs, and other essential habitats for marine life.

This special issue focuses on economic valuation of coastal and marine resource ecosystem services. Economic valuation is important because it provides methods and techniques to determine how changes in coastal and marine ecosystem services can be translated into benefits and costs to society. Economic values play an important role in everyday life and provide useful information about human happiness and welfare. Valuation provides a consistent framework to understand human-nature interactions across a broad range of coastal and marine resources, and to evaluate the sustainability of these interactions. The focus on ecosystem services provides new research on this innovative perspective on human-nature interactions that has profoundly changed the academic dialogue on natural systems, but has had limited impact on public dialogue and the policy process.

The practical importance of economic valuation information can hardly be overstated. Coastal and marine resource policy planning and management benefit from complete information on the impact of policy decisions. In addition, proper accounting of the impacts of these policy decisions is necessary for benefit-cost analyses and measurements of economic growth over time. 
The papers in this special issue provide new insights into ongoing research to value coastal and marine ecosystem services, and offer meaningful information for policymakers and resource managers about the economic significance of coastal resources for planning, restoration, and damage assessment. Study areas encompass a broad geographic scope from the Gulf of Mexico in the United States, to the Caribbean, the European Union, Australia, and Southeast Asia. The focus of these papers ranges from theoretical perspectives on linkages between ecosystem services and resource management, to the actual integration of valuation information in coastal and marine resource policy decisions, and to the application of economic valuation methods to specific coastal and marine resource management problems. We hope readers will appreciate these new contributions to the growing literature on coastal and marine resource ecosystem services valuation.

\section{Summary of the Papers}

This special issue contains seven papers. The first paper by Milon and Alvarez [2] provides an overview of the literature on valuation of coastal and marine ecosystem services, and the applications of valuation studies in policy and planning across the world. The authors begin with a description of the ecosystem services concept in the context of coastal and marine ecosystems, and the linkages between these ecosystem services and economic measures of use and nonuse values. The article focuses on prior literature that has attempted to identify economic values for ecosystem services and the use of these studies to estimate global values for coastal and marine ecosystems. This review indicates that there are significant gaps in the existing research, and there are few new efforts to fully integrate the relationships and feedbacks between ecosystems and the services they produce into economic valuation. A review of studies focusing on the application of economic valuation information for coastal and marine resource planning and policy in the United States, the Caribbean, the European Union, and Australia, reveals that valuation information is not widely understood and has had a negligible impact on the policy process. The authors conclude that the application and use of economic valuation information for coastal and marine resource planning and policy is not likely to advance until a more encompassing framework, such as wealth accounting, is adopted to evaluate human-nature interactions, the broad range of services provided by these ecosystems, and the impact of management decisions on sustainability.

Barbier [3] develops a theoretical framework to consider the impact of an open access fishery harvesting regulation on coastal habitat-dependent fishery stocks. The bioeconomic model integrates coastal breeding and nursery habitat availability with quota rules to limit the harvest of near-shore stocks. The model indicates that fixed quota rules fail to capture the changes in economic value due to interdependence between the habitat and fishery stocks, and a flexible management regime is necessary to achieve maximum economic yield. The modeling framework is applied to mangrove-dependent shellfish and demersal fishery species in Thailand. This analysis identifies significant differences in economic welfare when quota rules are not adjusted, and these effects vary across shellfish and demersal species. The article provides an important rationale for coastal and marine resource valuation studies to address the role of identifying and managing habitat to fishery linkages, and the dynamic relationships between habitat development and harvesting regulations.

Alvarez et al. [4] develop a random utility model to simulate changing recreational boating site choices as a result of harmful algae blooms (HABs) in coastal waters. The approach relies on survey data collected in the past to identify boater preferences for particular access ramps throughout a coastal county of the United States. The model controls for site attributes such as presence of artificial reefs, navigation aids, and no-wake zones to protect manatees, as well as protected status and water depth. The model is used to value site closures observed during recent cyanobacterial HABs caused by excess nutrients from human sources. Due to these nutrient loads and in synergy with historic surface water management (e.g., dredging and diking from urbanization and agriculture), the study area is suffering from chronic, semi-annual toxic HABs. Besides contributing to an emerging literature on the 
negative values of HABs, the article provides timely information on a topic of heightened public and policy-maker attention.

Schuhmann et al. [5] develop a stated behavior approach to measure visitors' willingness to return to Barbados in the future, using scenarios with different water quality, beach width, and coral reef health. While they find that visitors' intentions to return are impacted by changes in the three attributes examined, it is water quality that has the largest impact on intentions to return to Barbados. Further, large portions of respondents who had expressed they would definitely or probably return, later stated that even with small reductions in water quality they would definitely or probably not return. Their findings demonstrate that tourists' return visitation decisions are sensitive to declines in environmental quality, and provide justification for investments or regulations designed to maintain or improve environmental quality as measures to ensure the vitality of tourism in the region.

Maynard et al. [6] use a contingent valuation approach to value changes in coral ecosystems in a protected area in Taiwan that has experienced rapid and drastic deterioration as a result of nutrient pollution, overfishing, extreme weather, and coral bleaching. The approach considers both improvements in coral reef quality through restoration, as well as declines in coral reef quality due to further deterioration of the coral reef ecosystems in the protected area. To ensure that the respondents had an adequate understanding of the scenarios being considered, the approach uses photographs from areas within the protected area showing a progression of low to high coral coverage, and contribution to a coral protection trust is used as the payment vehicle. Their results indicate that respondents' willingness to pay for coral conservation increases with increasing coral coverage, and conversely, the marginal costs of degradation decrease with increasing coral coverage.

Seidel, Dourte, and Diamond [7] evaluate the use of remote sensing data in economic valuation using case studies across the Gulf of Mexico. Although remote sensing data is increasingly used for terrestrial ecosystem studies, applications for coastal and marine ecosystems have been limited. Their analysis is based on workshops with coastal managers and researchers across the Gulf States and valuation studies at National Estuary Program sites along the Atlantic and Gulf coasts of Florida. The workshops identified several barriers to adoption of remote sensing data in the Gulf region including: temporal and spatial gaps in the existing data, uncertainty about the precision of remote sensing data for coastal and marine resources, and the availability of economic valuation data for coastal and marine ecosystem services. The case studies focused on coastal resiliency and habitat restoration for coastal wetland and mangrove ecosystems. The valuation component employed a variety of benefit transfer methods including the use of InVEST, an ecosystem services valuation based software program that utilizes spatial data. Their evaluation indicates that remote sensing data can be successfully integrated into coastal and marine resource valuation studies, however, significant barriers must be overcome.

Conflicts of Interest: The authors declare no conflict of interest.

\section{References}

1. United Nations. Factsheet: People and Oceans. In Proceedings of the Ocean Conference, New York, NY, USA, 5-6 June 2017; Available online: https://www.un.org/sustainabledevelopment/wp-content/uploads/ 2017/05/Ocean-fact-sheet-package.pdf (accessed on 9 October 2019).

2. Milon, J.W.; Alvarez, S. The elusive quest for valuation of coastal and marine ecosystem services. Water 2019, 7, 1518. [CrossRef]

3. Barbier, E.B. Valuing coastal habitat-fishery linkages under regulated open access. Water 2019, 4, 847. [CrossRef]

4. Alvarez, S.; Lupi, F.; Solis, D.; Thomas, M. Valuing provision scenarios of coastal ecosystem services: the case of boat ramp closures due to harmful algae blooms in Florida. Water 2019, 6, 1250. [CrossRef]

5. Schuhumann, P.; Skeete, R.; Waite, R.; Bangwayo-Skeete, P.; Casey, J.; Oxenford, H.A.; Gill, D.A. Coastal and marine quality and tourists' stated intention to return to Barbados. Water 2019, 6, 1265. [CrossRef] 
6. Maynard, N.; Chateau, P.A.; Ribas-Deulofeu, L.; Liou, J.L. Using internet surveys to estimate visitors' willingness to pay for coral reef conservation in the Kenting National Park, Taiwan. Water 2019, 7, 1411. [CrossRef]

7. Seidel, V.; Dourte, D.; Diamond, C. Applying spatial mapping of remotely sensed data to valuation of coastal ecosystem services in the Gulf of Mexico. Water 2019, 6, 1179. [CrossRef] 